Article

\title{
Ensuring Sustainability of a Mobile Legacy Network by Im- proving Network KPIs using Six Sigma DMAIC Framework with AHP based Analysis
}

\author{
Malaya Kumar Mishra ${ }^{1}$, Tapan Kumar Das ${ }^{2}$, Kathiravan Srinivasan ${ }^{3}$ and Dushantha Nalin K. Jayakody ${ }^{4,5^{*}}$ \\ ${ }^{1}$ Department of Communication System, College of Engineering Bhubaneswar, Bhubaneswar, India; \\ mishra.malay@gmail.com \\ ${ }^{2}$ School of Information Technology and Engineering, Vellore Institute of Technology, Vellore, India ; ta- \\ pan.das@vit.ac.in \\ ${ }^{3}$ School of Computer Science and Engineering, Vellore Institute of Technology, Vellore, India; kathiravan.srin- \\ vasan@vit.ac.in \\ ${ }^{4}$ School of Computer Science and Robotics, National Research Tomsk Polytechnic University, Tomsk 634050, \\ Russia \\ ${ }^{5}$ Centre for Telecommunication Research, Faculty of Engineering, Sri Lanka Technological Campus, Sri Lanka \\ * Correspondence: nalin@tpu.ru
}

\begin{abstract}
Call set up success rate (CSSR) in a mobile network is an important quality parameter, which directly influences overall key performance indicators (KPIs) of the network service providers. Network KPIs especially the CSSR is the fraction of the attempts to make a call that result in a successful connection to the dialled number. Nevertheless, all call attempts do not end with a connection to the dialled number. In this research, six sigma methodology is applied to improve the call quality of a legacy mobile network and subsequently to boost comprehensive CSSR of a telecom service provider. This research elucidates an empirical study of improving overall CSSR by employing DMAIC methodology consisting of five stages, e.g. Define, Measure, Analysis, Improve and Control. In addition, analytic hierarchy process (AHP) technique is used for determining the vital causes out of all the identified network parameters affecting overall CSSR. Furthermore, the identified vital parameters are being upgraded in order to improve the overall CSSR and finally the system achieved a higher CSSR.
\end{abstract}

Keywords: analytic hierarchy process; call setup success rate; mobile network; quality of service; six sigma

\section{Introduction}

In mobile communication services, the regulators set the standards of service delivery and monitor its compliances. Besides, telecom service providers (TSPs) continuously explore the means of providing better services to their subscribers by constantly striving to boost the QoS in order to remain on top in the competition. Moreover, ensuring better services delivery by the TSP is essential as it would boost confidence of users and also meet demands of the loyal users. However, several factors bring down overall QoS delivery by the MNOs [1], few of them are call setup failures, signals loss, congestion, jitters call drops. In mobile networks, KPIs is a collection of several factors; e.g. CSSR, call drop rate (CDR), stand-alone dedicated control channel (SDCCH), call setup time (CST) and traffic channel (TCH) congestion [2]. These KPIs mirror the quality aspects of the network, these records are testimonial to achieve and maintain QoS-related issues. Periodical observations of these KPIs are highly essential as MNOs use these records to realise the QoS offered in a particular time period. In the other hand, subscribers use these KPIs to benchmark the services offered by the MNOs. These KPIs are mostly affected by increased congestions, due to various factors [3]. A mobile switching center (MSC) is a work unit larger 
than an individual workstation, and it is responsible for call set up, release and routing from base station. Typically, it has 3-12 people and 15-45 work stations in a compact arrangement. An ideal MSC does a narrow range of highly similar products /processes. Such an ideal MSC is self-contained with all necessary equipment and resources for processing of 2G, 3G, LTE and IMS calls. Mobile calls (2G, 3G, LTE, Volte), SMS, data browsing lines up in an initial queue when they enter the department. Such a group of sequential operations organized so that user initiated mobile operations are processed and subsequently transferred flawlessly that are maintained throughout the sequence of operations. Figure 1 depicts the detailed flow of call set up process.

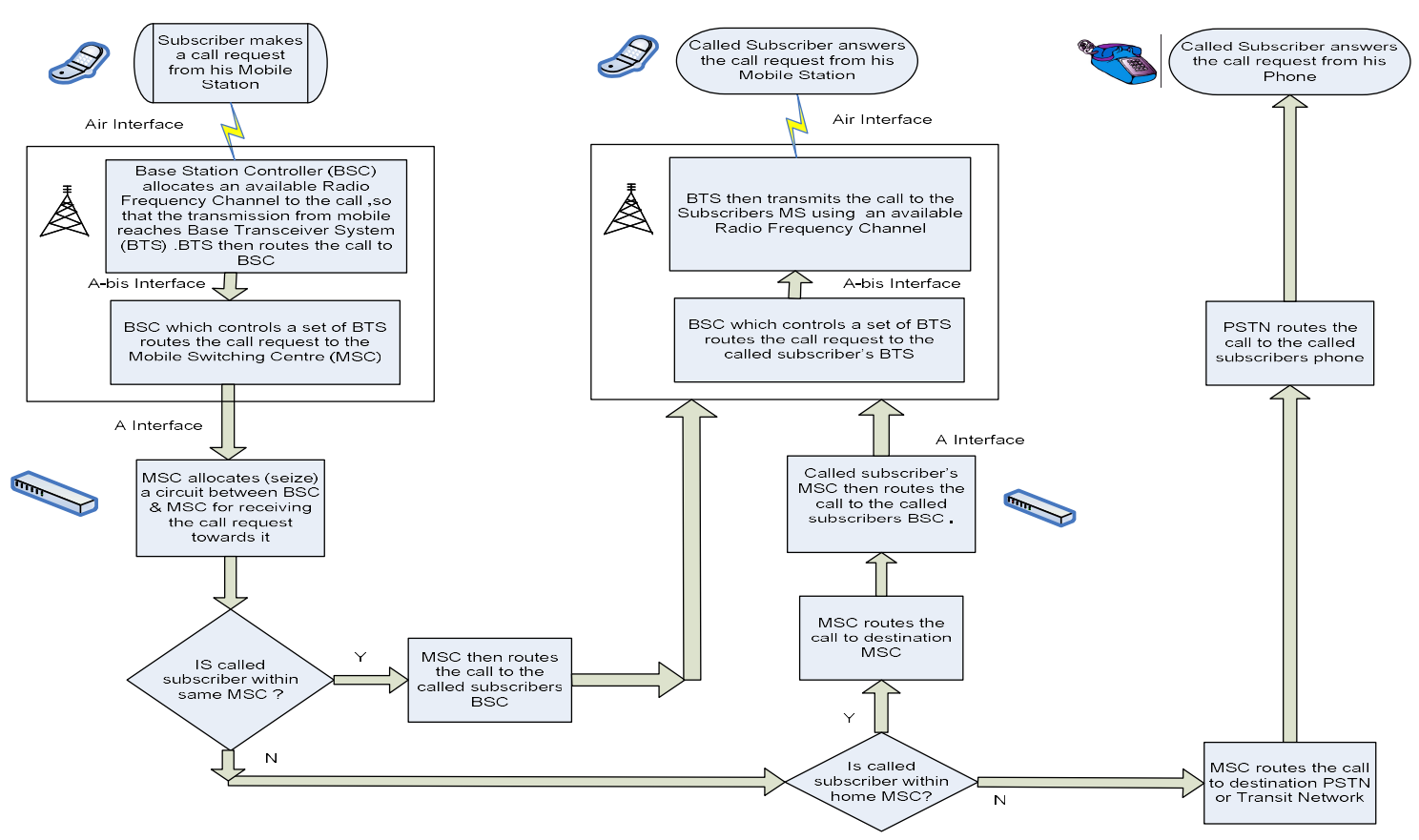

Figure 1. Micro level Flow.

Popoola et al. [4] in their research on the GSM networks, selected four MNOs as their primary sources of data. These MNOs were Celtel, MTN, Glo and M-Tel. They conducted the research on three KPIs which were CDR, CSSR and Call Completion Success Rate (CCSR). Furthermore, Pavan et al. [5] worked for an improvement by considering SDCCH KPI as a factor which affected QoS and they noticed that call initialization goes through three thematic processes, which also suffered inefficiencies.

Besides CSSR, paging success rate (PSR) and answered to seizure ratio (ASR) are the critical parameters to measure the performance of a network. ASR is the number of answered calls divided by the number of call attempts, Now here is the catch successful call is considered as once the call reaches the destination despite the number is busy or is not answering the call still the CSSR will be $1 / 1$ whereas the ASR is 0/1. If the call is answered and the conversation starts than the ASR will be 1/1 CSSR will be still 1/1. ASR and CSSR shows the network quality and the customer experience of the network. If these 2 parameters are benchmarked tracked and kept high the customer experience will be good and hence a mobile network will be considered best in class. Benefits of CSSR includes significant reduction in error rate; hence call success rate improvement occurs accordingly without any surge in workload. Due to workload reduction, required quicker identification of errors/deficiencies.

Our major contributions are listed below

- KPI analysis and monitoring process.

- Use of six sigma tools and technology. 
- Transmission connectivity with different entity.

- GSM Release cause analysis

The rest of the paper is organized as follows: Section 2 puts light on six sigma approach. The detailed case study along with DMAIC implementation is illustrated in Section 3. The paper is concluded in Section 4 along with future improvement.

\section{Six Sigma Process}

The term Sigma in statistics is used for featuring the distribution around the mean of a process, measures the variation and signifies the performance of the process. Analogously, Six sigma methodology equipped with DMAIC roadmap is being adopted by the manufacturing and service sectors in order to enhance the process quality paradigm and in turn to reduce the defects [6], [7]. By realizing the potential improvement of existing process capability, six sigma is implemented. Moreover, in manufacturing space, the process optimization includes controlling variation and defective products [6]-[8]. However, in the service sector, the employability of six sigma is focused to reduce human error, updating existing methodology and activities, minimizing system error, etc. Six sigma has been successfully implemented in various service domains; e.g. healthcare [9]- [13] , education [14]-[17], banking [18], [19], telecommunication [20], [21], logistics [22], [23].

Six sigma is a project-based approach, weighs heavily on employing scientific techniques in order to improve the output variables, applies to a system relying on one of the frameworks known as DMAIC- Define, Measure, Analyze, Improve and Control [24]; its stacking representation is shown in Figure 2. The data of an existing process in cross functional / uni-functional environment is subjected to these five phases, and finally the improvement is realized.

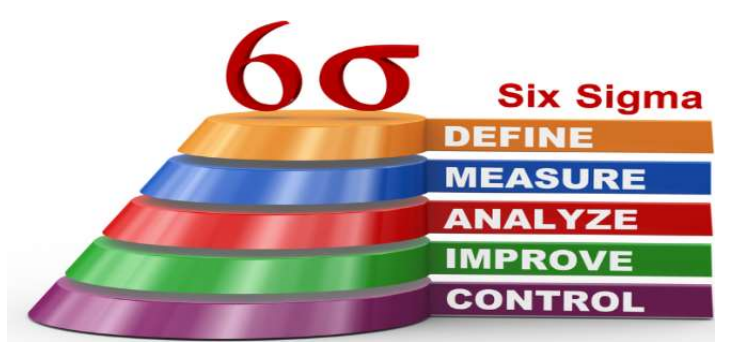

Figure 2. Six Sigma DMAIC Framework.

\section{Methodology and Approach}

\subsection{Problem Definition}

The case study has been conducted for TSP- Idea cellular network in the state of Odisha in the eastern region of India. The detailed architecture of cellular network is represented in Figure 3. It illustrates network connectivity of Idea Cellular Ltd for Odisha circle. MSC pool (MSC1and MSC2) includes the connection to controllers of 12 BSC's (10 TDM and 2 IP BSCs) by means of media-gateway MGW1 and MGW2. Multiple Core Network nodes with point code NI2-5560 and 5561 have been associated with BICC signalling through Node NE-40. 2G and 3G network is connected to Evolved Packet Core (EPC) architecture to connect users on a Long-Term Evolution (LTE) and IMS (IP multimedia services) network via IPRAN1 and IPRAN2. Further the MSS connected to SMSC for SMS (short message service) and Intelligent Network (IN) for prepaid services and their servers located at Kolkata associated through STP (signal transfer point) pair located at Durgapur and Kolkata. Access provider to make inter-circle / International Long Distance (ILD) calls through NLD router arrangements done for carrying a call from a PLMN Network situated in Odisha Telecom circle for call routing, handling and operations procedures two different vendors MGW's are located at Bhubaneswar for carrying NLD and ILD Calls and connected to respective MSC's located at Delhi. Within a service area, for routing intra circle calls the location of POI, established with other operators like Airtel, 
RJIO and BSNL for calls between PSTN and other TSPs. The steering of roaming solution provided by signalling based methods is being used by establishing connectivity with NTR and GLR for steering of their roaming traffic. For both in roamer and out roamer, for security auditing, billing or reporting purposes connected to its IT Cloud via Cisco Firewall and Cisco L3 switch.

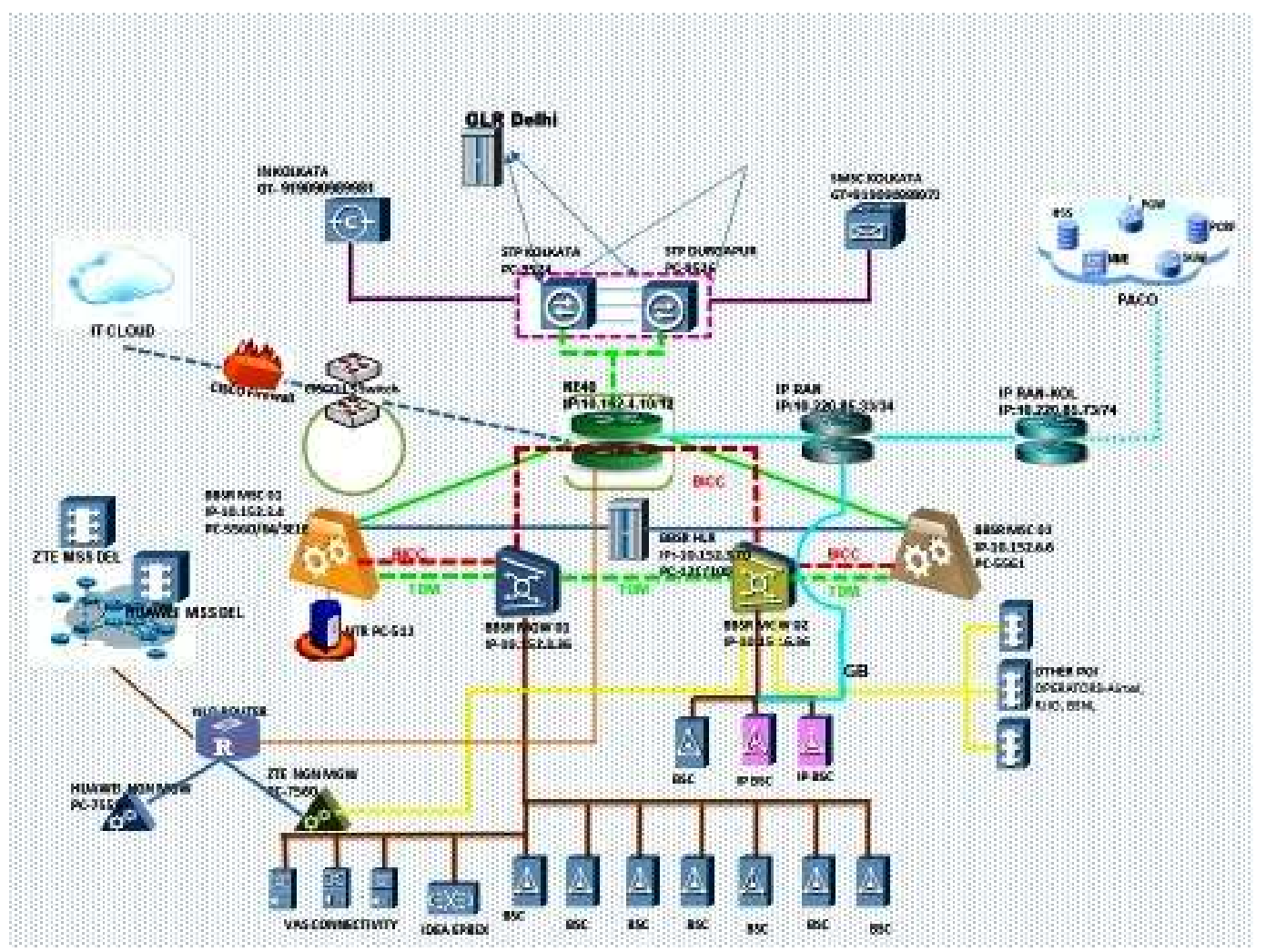

Figure 3. Cellular network architecture.

CSSR is an indicator of call connectivity in the mobile network, is a critical parameter affecting customer satisfaction and revenue. In order to achieve and meet this, it is important to work on switch parameters and all complex parameters. In between, 15th Sept 19 and 15th Dec 19, CSSR stands at $99.76 \%$ which means approximately $0.24 \%$ calls (50K calls) in the span of $24 \mathrm{Hr}$ gets failed in the network due to multiple reasons. The aim of the project was to increase CSSR of network to $99.97 \%$ by June 20 . In the current study, call setup failures due to technical issues within the network come under scope of the research. However, call setup failures due to external network or subscriber behaviour do not fall under the purview of our study.

\subsection{Measuring Current CSSR}

\subsubsection{Data Collection and Volume}

Unit of measurement: Monthly CSSR, calculated as a percentage on daily basis.

$\%$ CSSR, No. of successful calls, No. of calls

CSSR $=$ (No. of calls seized) $/$ (Total number of attempts)

Sample size in Months: Mid of September to mid of December and 100\% data is taken for baseline.

It is expedient for the interest of technology to say that from any mobile operators' switching centre equipment performance reports, it can be well analysed total day call failures in the network after perusing various raw reports and especially cause code report 
and preparing data there off. We have consolidated data by analyzing following raw reports from the system as listed below:

1. CPU SEIZURE RATE_STATS: CPU seizure rate statistics

2. PAGESUCRATE_STAT: Paging success rate statistics

3. FAILURE REASON_STAT: Failure reason statistics

4. M3UA LINKS TRAFIC: Signalling (M3UA) link traffic

5. CSSR_STAT: Call setup success rate

6. BSS_IN_STAT: Calls to base station from MSS statistics

7. BSS_OUT_STAT: Calls from base station to MSS

8. 8. BICC_OUT_STAT: Bearer independent call connectivity out statistics

9. BICC_IN_STAT: Incoming BICC statistics

10. IN_OFC_TRUNK_DIR_SIP: Office trunk direction session initiation protocol

11. BICC_INCOMING_TRAFFIC: Incoming traffic of BICC

12. BICC_OUTGOING_TRAFFIC: Outgoing traffic of BICC

13. TRAFFIC_MEASUREMENT_FOR_LAI: Traffic for location area identity

14. GLOBAL_CALL_FAILURE_CAUSES: Call failure causes

15. SD CONGETION_STAT: SDCCH Channel congestion statistics

Furthermore, we properly analysed cause code failure report, LAC wise PSR report, destination dialing report and other equivalents, inspected the analyser for further performance management and other alarm, looked over the fault management and also connected to other ancillary information. Such dates are procured by logging in the performance management system of MSS, MGW and UDR and sending query commands and timeline etc. It is important to consider the volume in a guided and sophisticated manner, to do the same with some fixed time instead of round the clock. It is also equally important to know the callers' psychology for their engagement in different climate, environment and the like so. It is good enough to consider the same based on the season where in one can expect maximum call seizures/attempts. Experience says that the call seizure is high in between time consistent busy hours (TCBH) time, which has to be considered at various places in globe and at the different time as per the time zone.

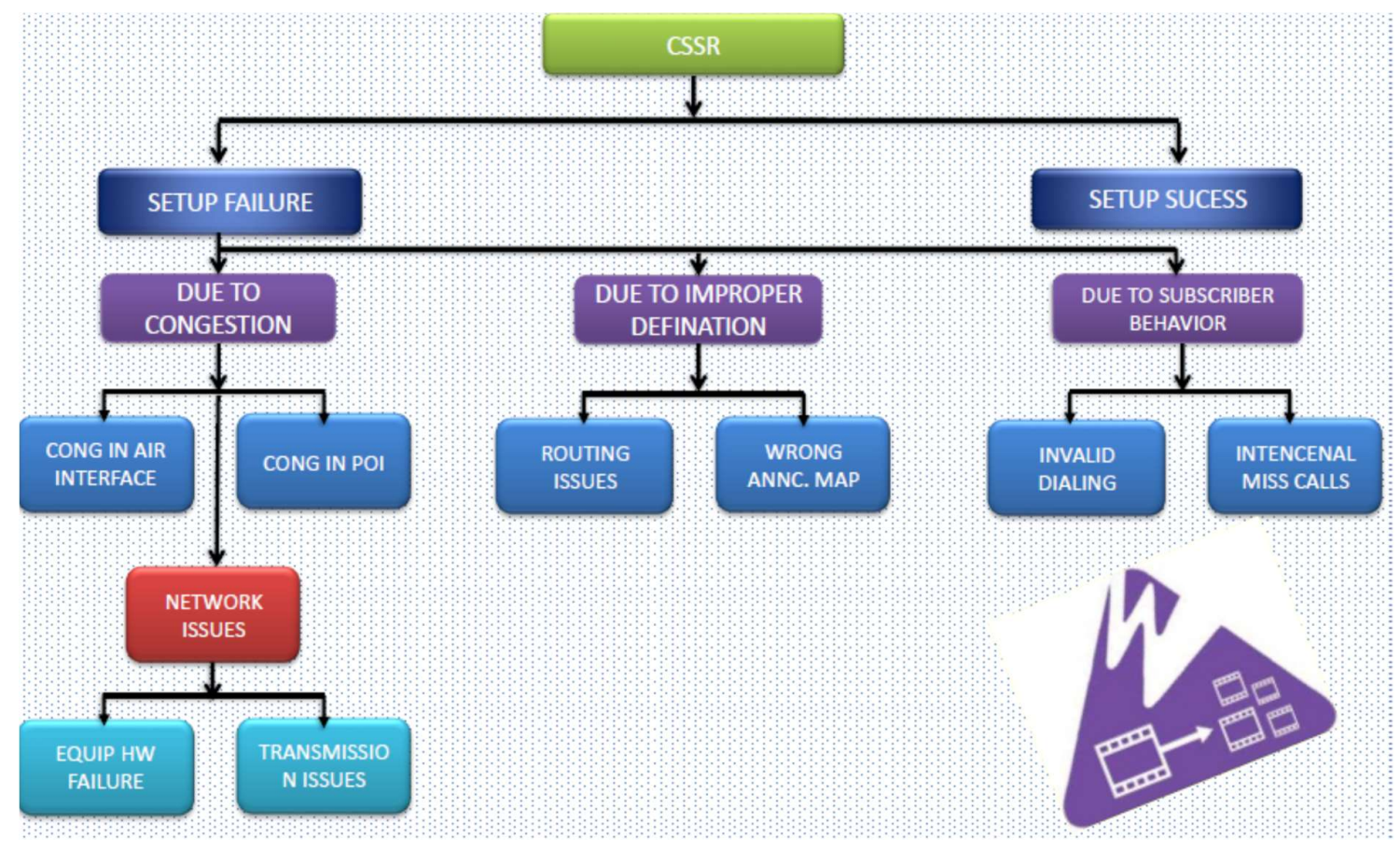

Figure 4. Characterization of CSSR. 
Figure 4 shortly and understandably represents CSSR. While preparing CSSR diagram, emphasis is given in two phases. In one phase, it represents setup failure and in second phase it represents setup success as intended by the author. The set up failure is more fully described in downward and size ward step in graphical representation. Accordingly in the CSSR failure system, we have identified following issues:

- Due to congestion

- Due to improper definition

- Due to subscriber behavior

- Congestion in air interface

- Congestion in POI

- Network issues

- Equipment hardware failure

- Transmission issues

- Routing issues

- Wrong announcement Map

- Invalid dialling

- Intentional miss call

\subsection{Root Cause Analysis of Call Drop}

Fish bone diagram is mostly utilised for cause effect analysis [25], useful in identifying possible contributing causes to occur for a problem and those causes are being grouped into different categories [26]. The major problem is represented along the mouth of the fish [27]. In our case, CSSR is placed along the head of the fish. Next, the major causes are identified, they are machine, material, environment, method and human error and they are represented as branches from main arrow. All other individual causes are represented as bones and they are put in either of the identified five causes. For an example; far end congestion, level opening issues, circuit congestion, parameter mismatch, improper digit length are being identified as member of category "machine".

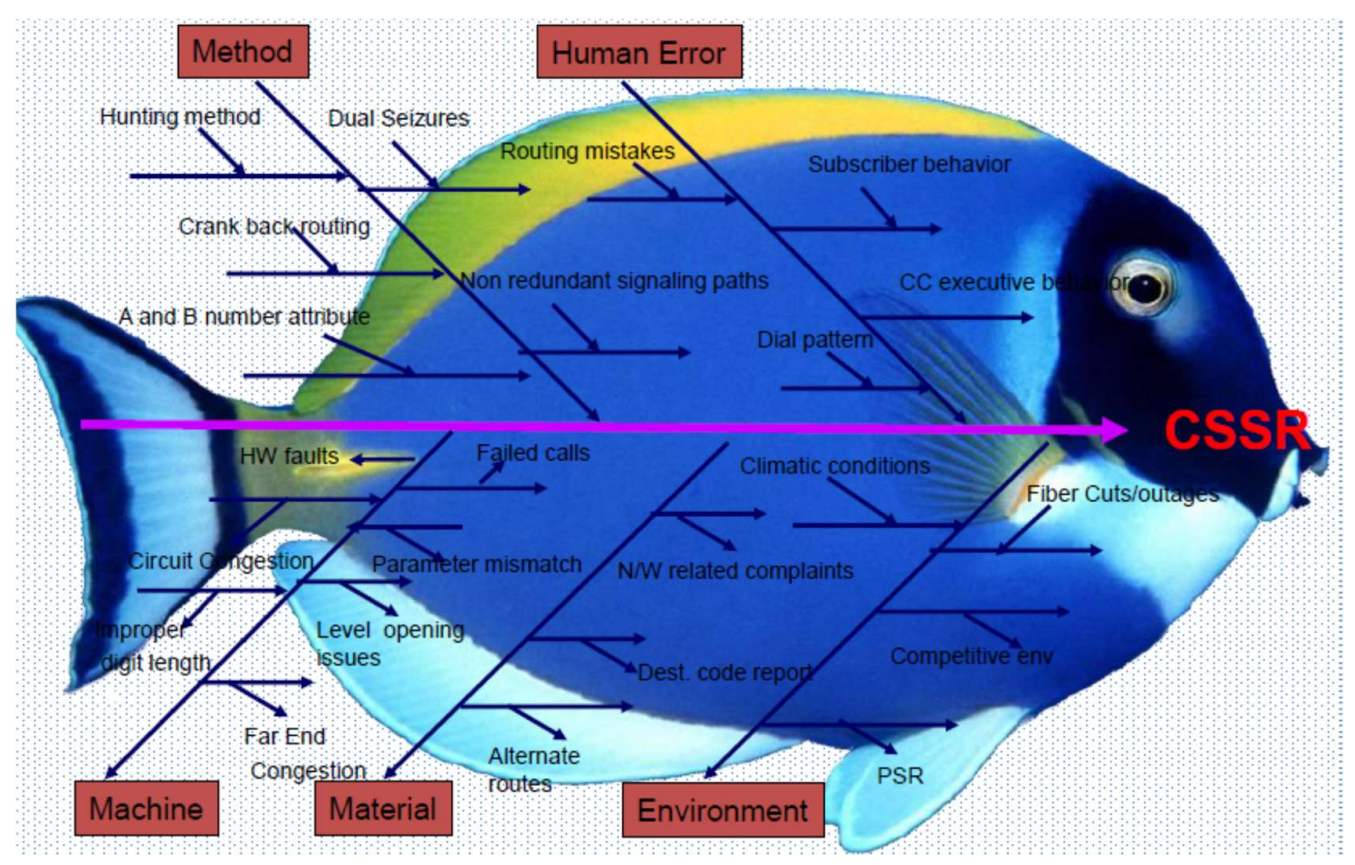

Figure 5. Fish Bone Analysis.

Similarly, numerous causes are identified by brainstorming, consulting with team members having knowledge of the ensuing system and the underlying process, subsequently they are assigned to one of the remaining branches of fish e.g. human error, 
method, machine, material and environment and the detailed representation is shown in Figure 5 .

\subsubsection{Analytic Hierarchy Process (AHP)}

AHP is suitable for analysis of a problem which consists of the variables whose weightages are to be prejudiced by human decision makers [28]. This kind of investigation is known as Multi-Criteria Decision Analysis (MCDA) approach [29]. Even though, quite a number of MCDA techniques are in practice, however, popularity of AHP is attributed to its simple, structured and systematic evaluation [30] roadmap. The generic flow of AHP is shown in Figure 6. Moreover, AHP passes through phases of decomposition, prioritization and weight determination.

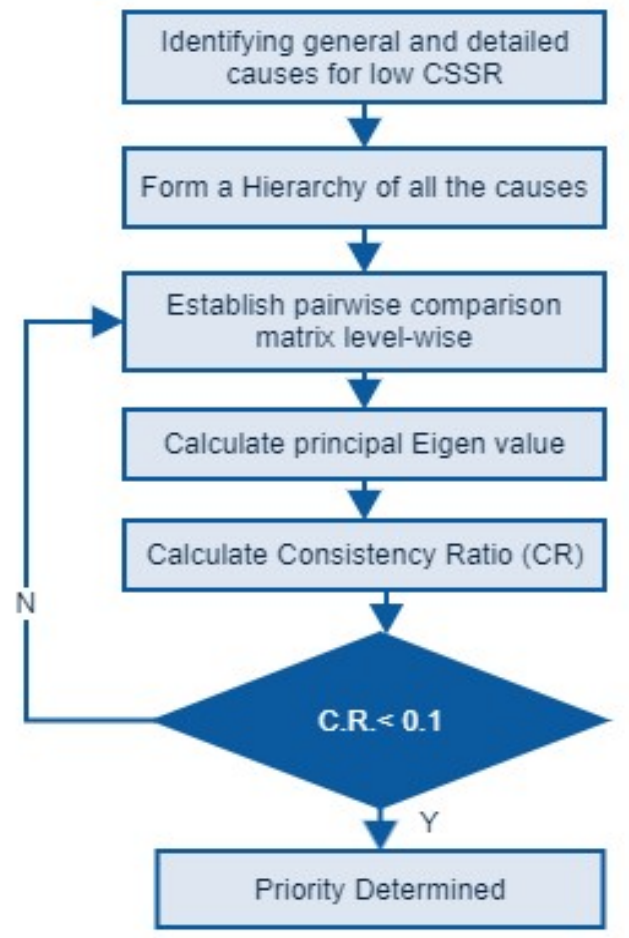

Figure 6. Detailed AHP approach.

Decomposition

In this phase, a hierarchical structure is framed such that Level 1 of the hierarchy is positioned by CSSR since the attainment of high value of CSSR is the aim of the study.

Next, in Level 2, the general categories, e.g. method, machine, material, human error and environment are placed followed by level 3, where the above parameters are further decomposed into detailed causes and the full hierarchy is shown in Table 1 . The analysis of splitting up was carried out by one of the authors along with his colleagues working in Vodafone Idea Company.

Table 1. Hierarchy of parameters affecting CSSR.

\begin{tabular}{ccc}
\hline Level 1 & Level 2 & Level 3 \\
\hline & & Dual Seizure (DS) \\
CSSR & Method & Crank Back Routing (CBR) \\
& & Signalling Issues (SI) \\
& & Level Opening Issues (LOI) \\
\cline { 2 - 3 } & Human Error & Wrong Dial Pattern (WDP) \\
\hline
\end{tabular}


Meet Error in Send routing (MES)

No Route to Callee (NRC)

No Route Available (NRA)

\begin{tabular}{cc}
\hline & No Route or Circuit Available (NRCA) \\
& Failure due to Termination Error (FTE) \\
Machine & Parameter Mismatch (PM) \\
& Switch Equipment Congestion (SEC) \\
& Call Rejection from Peer end (CRP) \\
& Timer Recovery (TR) \\
\hline \multirow{2}{*}{ Material } & Assignment Failure (AF) \\
& No Respond from Peer end (NRP) \\
\hline \multirow{2}{*}{ Environment } & Unsuccessful Paging (USP) \\
& Outage due to Fibre Cut (OFC)
\end{tabular}

\section{Prioritization}

First, causes in level 2 are prioritized in order to create a pairwise comparison matrix (PCM), and it is shown in Table 2. From the second row of the table, the intersection cell between method and machine is of the value 9, indicates method is nine times significant than machine for CSSR. Likewise, weightage of method is three times than that of material and weightage of method is five times of environment. In the same way, all the causes placed in level 3 are prioritized, and it is exhibited as PCM in Table 3.

Table 2. Level 2 PCM.

\begin{tabular}{cccccc}
\hline & Machine & Method & Material & Environment & Human Error \\
\hline Machine & 1 & 0.11 & 0.33 & 0.2 & 0.25 \\
Method & 9 & 1 & 3 & 5 & 3 \\
Material & 3 & 0.33 & 1 & 0.33 & 0.5 \\
Environment & 5 & 0.2 & 3 & 1 & 1 \\
Human Error & 4 & 0.33 & 2 & 2 & 1 \\
\hline
\end{tabular}

Table 3. Level3 PCM.

\begin{tabular}{|c|c|c|c|c|c|c|c|c|c|c|c|c|c|c|c|c|c|c|}
\hline & WDP & DS & MES & NRCA & FTE & PM & USP & OFC & SI & NRC & CBR & LOI & AF & SEC & NRA & NRP & CRP & TR \\
\hline WDP & 1 & 2 & 0.2 & 0.2 & 0.33 & 1 & 0.14 & 4 & 2 & 1 & 2 & 0.14 & 0.2 & 1 & 0.2 & 1 & 1 & 2 \\
\hline DS & 0.5 & 1 & 0.33 & 0.2 & 0.33 & 2 & 0.2 & 4 & 2 & 6 & 2 & 0.14 & 0.2 & 1 & 0.33 & 1 & 2 & 4 \\
\hline MES & 5 & 3 & 1 & 4 & 2 & 5 & 6 & 3 & 3 & 5 & 5 & 4 & 2 & 3 & 2 & 3 & 5 & 3 \\
\hline NRCA & 5 & 5 & 0.25 & 1 & 4 & 3 & 4 & 5 & 3 & 3 & 5 & 6 & 4 & 3 & 2 & 5 & 5 & 3 \\
\hline FTE & 3 & 3 & 0.5 & 0.25 & 1 & 3 & 6 & 3 & 1 & 5 & 3 & 2 & 2 & 3 & 1 & 3 & 5 & 3 \\
\hline PM & 1 & 0.5 & 0.2 & 0.33 & 0.33 & 1 & 0.2 & 1 & 2 & 1 & 4 & 0.14 & 0.2 & 1 & 0.33 & 1 & 2 & 1 \\
\hline USP & 7 & 5 & 0.17 & 0.25 & 0.17 & 5 & 1 & 3 & 5 & 3 & 3 & 2 & 4 & 5 & 2 & 3 & 3 & 5 \\
\hline OFC & 0.25 & 0.25 & 0.33 & 0.2 & 0.33 & 1 & 0.33 & 1 & 1 & 0.5 & 0.3 & 0.14 & 0.2 & 2 & 0.33 & 2 & 1 & 2 \\
\hline SI & 0.5 & 0.5 & 0.33 & 0.33 & 1 & 0.5 & 0.2 & 1 & 1 & 0.3 & 0.5 & 0.2 & 0.14 & 1 & 0.2 & 1 & 0.3 & 0.5 \\
\hline NRC & 1 & 0.17 & 0.2 & 0.33 & 0.2 & 1 & 0.33 & 2 & 4 & 1 & 1 & 0.33 & 0.2 & 2 & 0.33 & 2 & 1 & 3 \\
\hline CBR & 0.5 & 0.5 & 0.2 & 0.20 & 0.33 & 0.3 & 0.33 & 4 & 2 & 1 & 1 & 0.33 & 0.14 & 1 & 0.2 & 0.5 & 2 & 0.3 \\
\hline LOI & 7 & 7 & 0.25 & 0.17 & 0.5 & 7 & 0.5 & 7 & 5 & 3 & 3 & 1 & 2 & 5 & 4 & 7 & 5 & 3 \\
\hline $\mathrm{AF}$ & 5 & 5 & 0.5 & 0.25 & 0.5 & 5 & 0.3 & 5 & 7 & 5 & 7 & 0.5 & 1 & 7 & 2 & 3 & 5 & 3 \\
\hline SEC & 1 & 1 & 0.33 & 0.33 & 0.33 & 1 & 0.2 & 0.5 & 1 & 0.5 & 1 & 0.2 & 0.14 & 1 & 0.14 & 1 & 2 & 4 \\
\hline NRA & 5 & 3 & 0.5 & 0.5 & 1 & 3 & 0.5 & 3 & 5 & 3 & 5 & 0.25 & 0.5 & 7 & 1 & 5 & 3 & 3 \\
\hline NRP & 1 & 1 & 0.33 & 0.2 & 0.33 & 1 & 0.33 & 0.5 & 1 & 0.5 & 2 & 0.14 & 0.33 & 1 & 0.2 & 1 & 2 & 1 \\
\hline CRP & 1 & 0.5 & 0.2 & 0.2 & 0.2 & 0.5 & 0.33 & 1 & 4 & 1 & 0.5 & 0.2 & 0.2 & 0.5 & 0.33 & 0.5 & 1 & 1 \\
\hline TR & 0.5 & 0.25 & 0.33 & 0.33 & 0.33 & 1 & 0.2 & 0.5 & 2 & 0.3 & 4 & 0.33 & 0.33 & 0.3 & 0.33 & 1 & 1 & 1 \\
\hline
\end{tabular}




\section{Weight Determination}

This phase involves the computation of the weights of identified causes placed in level 2 and level 3 by calculating respective Eigen values. Firstly, the values in each column of the PCM are summed up. Secondly, each element in the PCM is divided by its column total. Third, the average of the elements in each row of the PCM are calculated. These three steps are executed for the entries in Table 2, consequently, the weights of parameters machine, method, material, environment and human error are obtained and it is represented graphically in Figure 6

Table 4. Resulting weights for the criteria in level 2.

\begin{tabular}{ccccc}
\hline Categories & Weightage & Rank & $\mathbf{( + )}$ & $(\mathbf{- )}$ \\
\hline Machine & $4 \%$ & 5 & $0.9 \%$ & $0.9 \%$ \\
Method & $49.1 \%$ & 1 & $19.6 \%$ & $19.6 \%$ \\
Material & $10.3 \%$ & 4 & $3.7 \%$ & $3.7 \%$ \\
Environment & $16.5 \%$ & 3 & $8.2 \%$ & $8.2 \%$ \\
Human Error & $20.1 \%$ & 2 & $6.6 \%$ & $6.6 \%$ \\
\hline
\end{tabular}

The resulting weights for the categories based on pairwise comparison also represented in Table 4 . It is pertinent from the result that category method has highest preference of $49.1 \%$ followed by human error having $20.1 \%$ priority. The Consistency Ratio (CR) calculated as $6.2 \%(0.062)$ which is below than 0.1 indicating viability and validity of our experimental result. The principal Eigen value is 5.281.

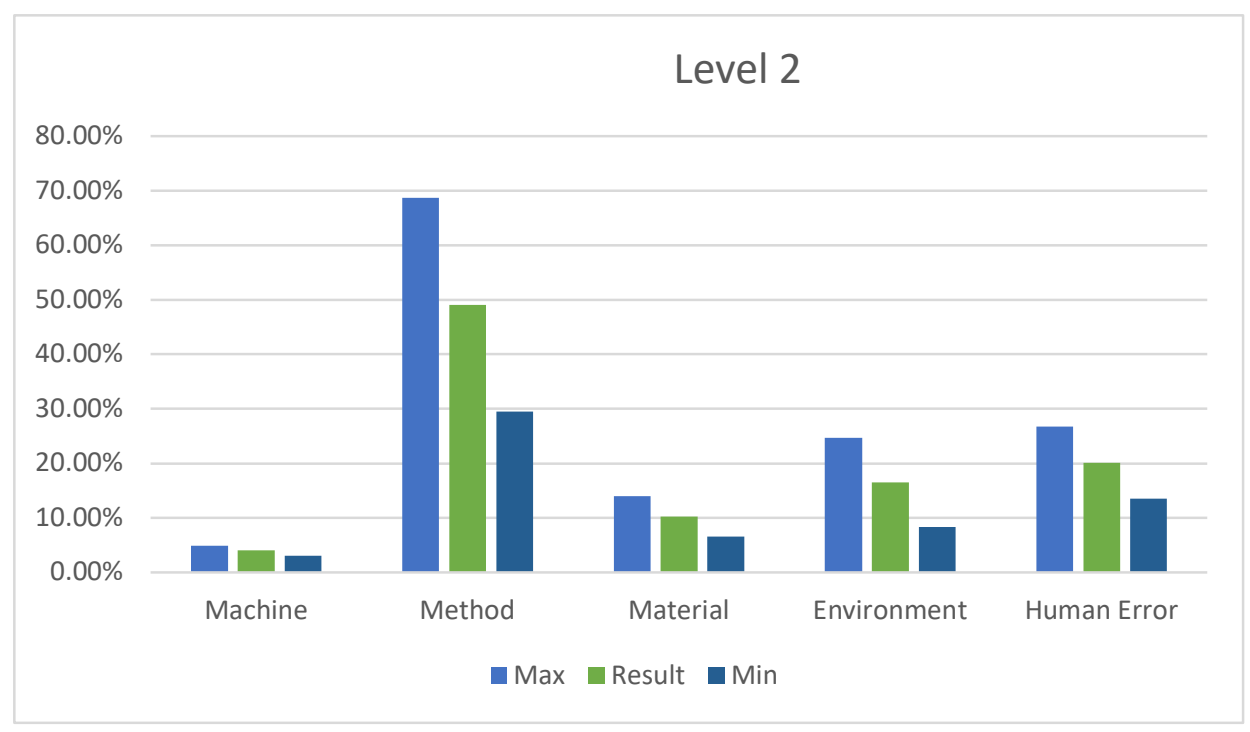

Figure 7. Priorities of Level 2 parameters.

In the same way, priorities for all the causes present in level 3 based on pairwise comparisons are calculated and they are presented in Table 5. The obtained CR value is $9.4 \%$ which is less than $10 \%$ reflects the validity of our experimental result. Principal Eigen value is 20.58. The results are also shown graphically in Figure 7. 
Table 5. Resulting weights for the causes in level 3.

\begin{tabular}{|c|c|c|c|c|c|}
\hline Sl. No & Causes & Priority & Rank & $(+)$ & $(-)$ \\
\hline 1 & WDP & $2.80 \%$ & 10 & $1.60 \%$ & $1.60 \%$ \\
\hline 2 & DS & $3.10 \%$ & 8 & $1.80 \%$ & $1.80 \%$ \\
\hline 3 & MES & $13.50 \%$ & 1 & $11.10 \%$ & $11.10 \%$ \\
\hline 4 & NRCA & $12.90 \%$ & 2 & $9.80 \%$ & $9.80 \%$ \\
\hline 5 & FTE & $8.30 \%$ & 6 & $4.10 \%$ & $4.10 \%$ \\
\hline 6 & PM & $2.70 \%$ & 11 & $1.70 \%$ & $1.70 \%$ \\
\hline 7 & USP & $10.60 \%$ & 4 & $7.00 \%$ & $7.00 \%$ \\
\hline 8 & OFC & $2.20 \%$ & 14 & $1.10 \%$ & $1.10 \%$ \\
\hline 9 & SI & $1.80 \%$ & 18 & $1.00 \%$ & $1.00 \%$ \\
\hline 10 & NRC & $3.10 \%$ & 9 & $1.30 \%$ & $1.30 \%$ \\
\hline 11 & CBR & $2.60 \%$ & 12 & $1.60 \%$ & $1.60 \%$ \\
\hline 12 & LOI & $11.20 \%$ & 3 & $6.00 \%$ & $6.00 \%$ \\
\hline 13 & $\mathrm{AF}$ & $9.40 \%$ & 5 & $4.30 \%$ & $4.30 \%$ \\
\hline 14 & SEC & $2.40 \%$ & 13 & $1.40 \%$ & $1.40 \%$ \\
\hline 15 & NRA & $7.30 \%$ & 7 & $3.10 \%$ & $3.10 \%$ \\
\hline 16 & NRP & $2.20 \%$ & 15 & $0.80 \%$ & $0.80 \%$ \\
\hline 17 & CRP & $2.10 \%$ & 16 & $1.20 \%$ & $1.20 \%$ \\
\hline 18 & TR & $2.00 \%$ & 17 & $1.00 \%$ & $1.00 \%$ \\
\hline
\end{tabular}

Level 3

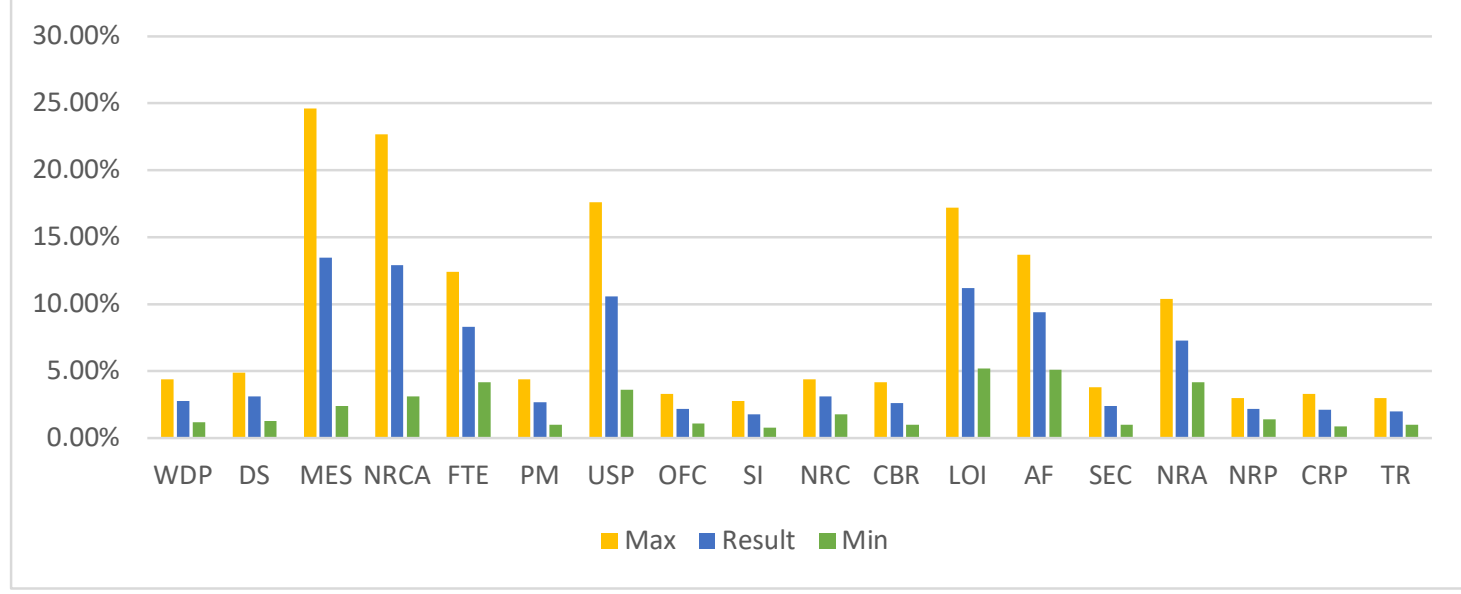

Figure 8. Priorities of Level 3 parameters.

Figure 13. 5\% followed by NRCA, LOI, USP, AF, FTE and NRA.

Next, considering all the possible causes e.g. Technical problems, subscriber's behavior and external factors, we have investigated the past data to realize the weightages of each factors, now basing on the data, we have drawn a Pareto chart [31] to identify the most frequent root causes. A Pareto Chart shows the frequency with which different signalling release causes occurs. It is a bar graph where each frequency (or frequency range) is shown in a descending order of importance of causes, from left to right. This is based on the Pareto principle, also called 80-20 rule or rule of vital few. It's useful to find the defects to prioritize in order to observe the overall CSSR improvement in a mobile network. Likewise, Pareto chat from Figure 9 reveals first six causes amounts to $79 \%$ of the issues. The prominent root causes are Release before answer (38\%), user decide to busy $(11 \%)$, Release before ring $(9 \%)$ and No acknowledge from callee $(8 \%)$. 


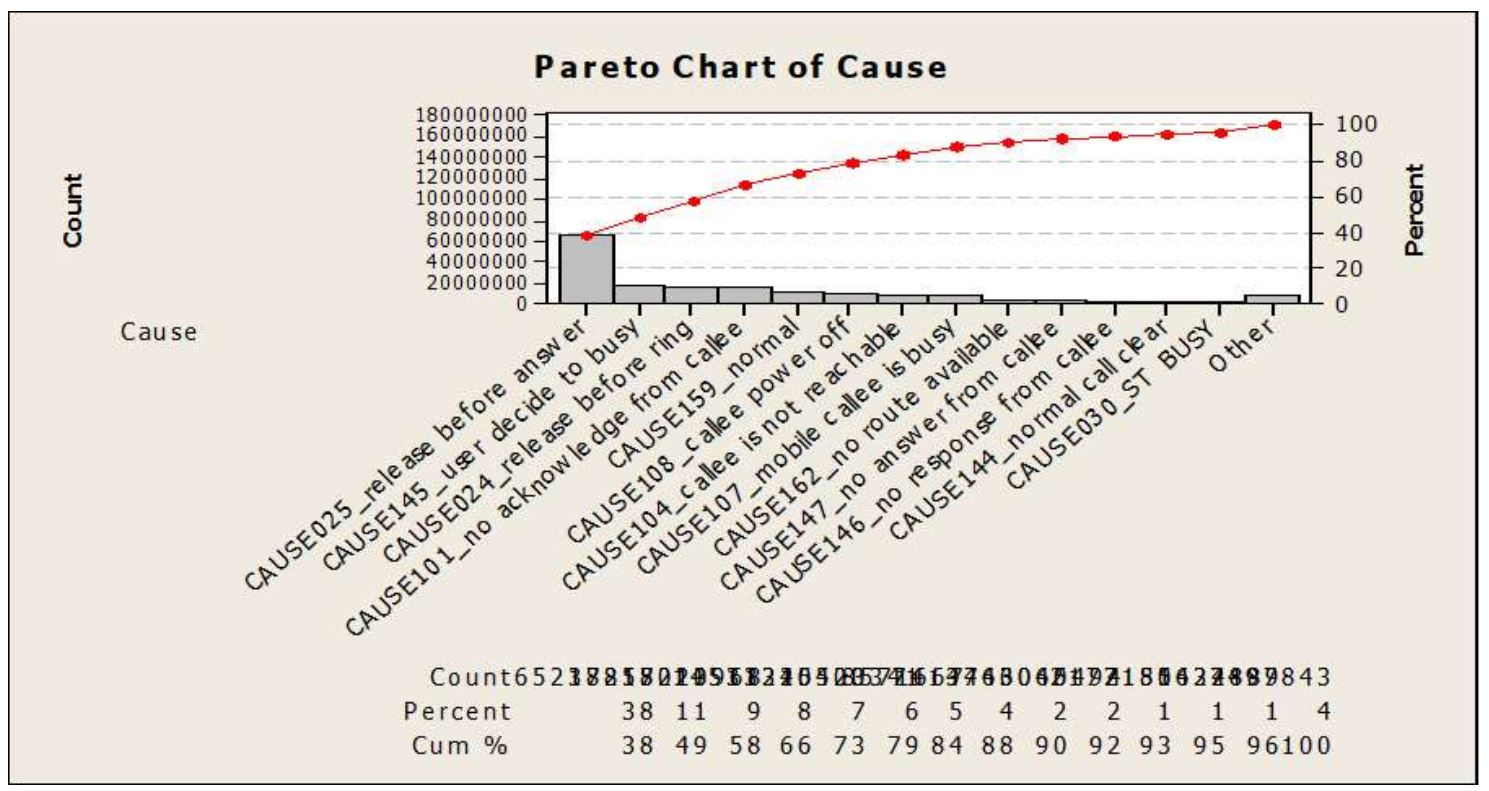

Figure 9. Pareto Chart for Cause analysis.

After all the possible causes are identified, a brainstorming session with the team members was organized and after a complete discussion, whether the root causes can be countered or not along with their impacts are tabulated and it is represented in Table 6 .

Table 6. Causes and their Impacts.

\begin{tabular}{|c|c|c|c|}
\hline \multirow{2}{*}{ Causes } & Controllable & Measurable & Impact \\
\hline & $\mathbf{Y} / \mathbf{N}$ & $\mathbf{Y} / \mathbf{N}$ & $\mathrm{H} / \mathrm{M} / \mathrm{L}$ \\
\hline Wrong dial pattern of subscriber & $\mathrm{Y}$ & $\mathrm{N}$ & $\mathrm{L}$ \\
\hline Dual seizure & $\mathrm{Y}$ & $\mathrm{Y}$ & $\mathrm{H}$ \\
\hline Meet error in send routing info procedure & $\mathrm{Y}$ & $\mathrm{Y}$ & $\mathrm{H}$ \\
\hline No route or circuit applied available & $\mathrm{Y}$ & $\mathrm{Y}$ & $\mathrm{H}$ \\
\hline Failure due to termination error & $\mathrm{N}$ & $\mathrm{Y}$ & $\mathrm{H}$ \\
\hline Parameter mismatch & $\mathrm{Y}$ & $\mathrm{N}$ & $\mathrm{H}$ \\
\hline Unsuccessful paging & $\mathrm{Y}$ & $\mathrm{Y}$ & $\mathrm{H}$ \\
\hline Outages due to fibre cut/hardware fault & $\mathrm{Y}$ & $\mathrm{Y}$ & $\mathrm{M}$ \\
\hline Signalling issues & $\mathrm{Y}$ & $\mathrm{N}$ & $\mathrm{M}$ \\
\hline No route to the callee & $\mathrm{Y}$ & $\mathrm{Y}$ & $\mathrm{H}$ \\
\hline Crank back routing & $\mathrm{Y}$ & $\mathrm{N}$ & $\mathrm{M}$ \\
\hline Level opening issues & $\mathrm{Y}$ & $\mathrm{N}$ & $\mathrm{H}$ \\
\hline Assignment failure & $\mathrm{Y}$ & $\mathrm{Y}$ & $\mathrm{H}$ \\
\hline SRI failure & $\mathrm{N}$ & $\mathrm{Y}$ & $\mathrm{H}$ \\
\hline Switch equipment congestion & $\mathrm{N}$ & $\mathrm{N}$ & $\mathrm{M}$ \\
\hline No route available & $\mathrm{Y}$ & $\mathrm{Y}$ & $\mathrm{H}$ \\
\hline Meet error in send routing info procedure & $\mathrm{Y}$ & $\mathrm{Y}$ & $\mathrm{H}$ \\
\hline Operator determined barring & $\mathrm{Y}$ & $\mathrm{Y}$ & M \\
\hline Unallocated DN & $\mathrm{N}$ & $\mathrm{Y}$ & $\mathrm{M}$ \\
\hline No response from peer end & $\mathrm{N}$ & $\mathrm{Y}$ & $\mathrm{H}$ \\
\hline Call rejection from peer end & $\mathrm{N}$ & $\mathrm{Y}$ & $\mathrm{H}$ \\
\hline Network error & $\mathrm{N}$ & $\mathrm{N}$ & $\mathrm{M}$ \\
\hline Protocol error & $\mathrm{N}$ & $\mathrm{Y}$ & $\mathrm{H}$ \\
\hline Timer recovery & $\mathrm{Y}$ & $\mathrm{Y}$ & $\mathrm{H}$ \\
\hline
\end{tabular}

Impact control matrix relates to the ways and means and to understand factors for cent percentage success in call set up from source to sink and the reasons of 
failure/decrease of the same. Various factors are responsible and various factors also controls such call setup from source to sink. For e.g if a caller dials to a callee even if the handsets are perfect in all respect, there is change of misdialling like dialling 9 digit number instead of 10 digit causing set back to the said call. Similarly other factors which are narrated below are responsible for setback of failure of calls. Those main causes are represented in a matrix form in Figure 9 for better understanding

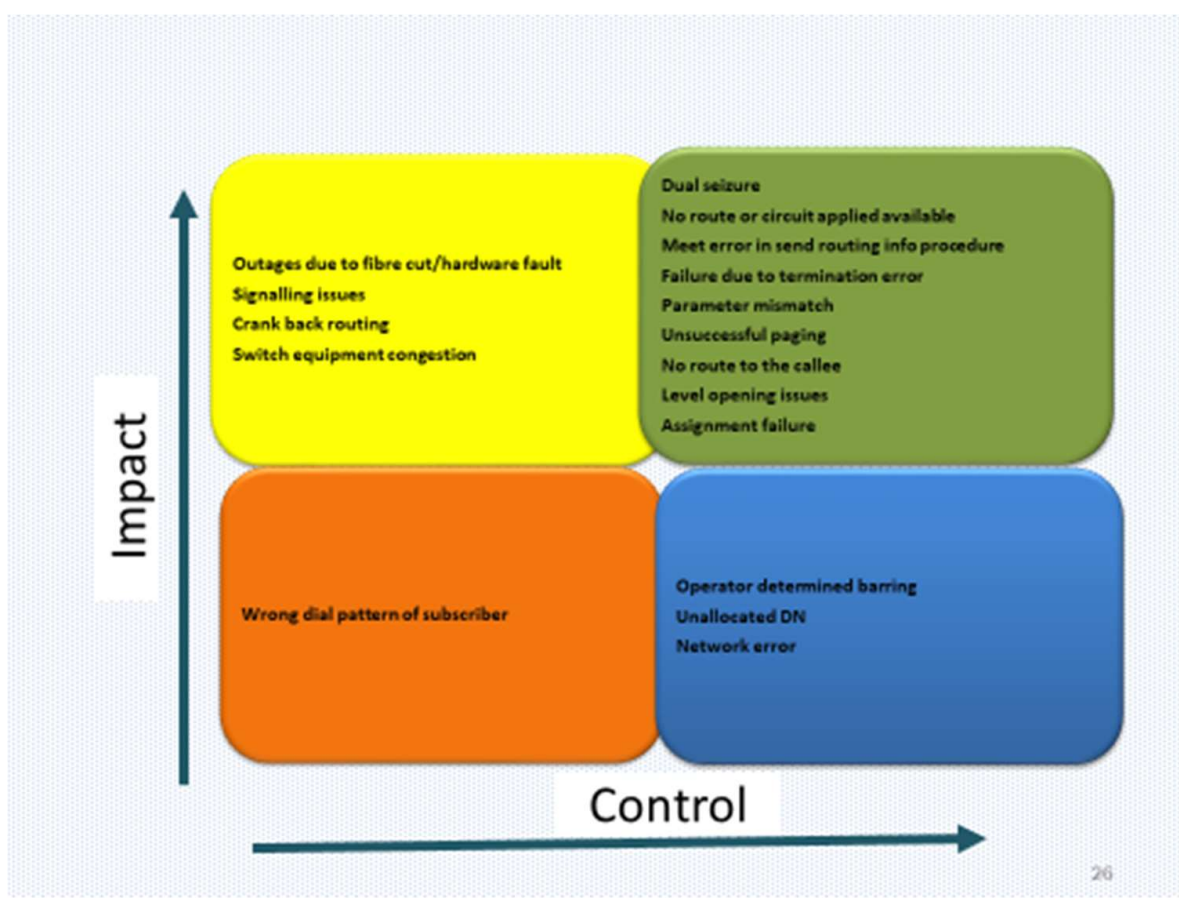

Figure 10. Impact Control Matrix.

\subsection{Strategic Improvment}

From the root cause analysis section; from Table 5 and subsequently from Figure 7, the causes having more than $5 \%$ weightages are targeted in order to improve them so that overall CSSR value will be boosted. Now, we have seven vital causes whose priorities are greater than $5 \%$. These vital causes are listed below:

- Meet error in send routing info procedure

- No route or circuit applied available

- Failure due to termination error

- Assignment failure

- $\quad$ Level opening issues

- No route available

- Unsuccessful paging

Any technology never and cannot be allowed to remain static without further improvement and innovative efficiency. Similar is the case of call set up through mobile communication. Mobile communication is involved in sending message and to be recovered the same to complete its cycle. Message is sent in signalling system i.e. by electromagnetic wave through standard through instrument which can send and receive such signal. In process signals are send through binary 0,1 coding system and received it being decoded. Whatever the case may be some errors in instrument, signalling process, transmission are bound to occur due to various reasons and factors and though reasons and factors needs to be eradicated for its development and output efficiency. Therefore observation, experiment and inferences are always necessary for developing the system time and again. The errors, its eradication and to get more input of efficiency, the measures undertaken are described in Table 7. 
Table 7. Corrective measures implemented against vital causes.

\begin{tabular}{|c|c|}
\hline Vital causes & Action taken \\
\hline Meet error in send routing info procedure & Mobile application part(MAP) report analysis and DN Flag change \\
\hline No route or circuit applied available & $\begin{array}{l}\text { Complete B- table audit done and also checked with different national long distance } \\
\text { (NLD) carriers regarding opening of the same if not changed the route with RA } \\
\text { concern }\end{array}$ \\
\hline Failure due to termination error & $\begin{array}{l}\text { Analyzed subscriber definition for barring and with other operator's also by taking } \\
\text { trace and resolved accordingly }\end{array}$ \\
\hline Assignment failure & $\begin{array}{l}\text { Assignment Failure are mostly from BSC side same has been checked with detailed } \\
\text { analysis to BSS team after parametric modifications from BSS end failure has been } \\
\text { decreased drastically. }\end{array}$ \\
\hline Level opening issues & $\begin{array}{l}\text { On allocation of new level most of the circle operators are not aware of the same, } \\
\text { continuous follow up has been done to get the new levels opened with tracker. }\end{array}$ \\
\hline No route available & $\begin{array}{l}\text { Most of the time we have observed No route available for some NLD numbers same } \\
\text { has been followed up with concerned team and resolved }\end{array}$ \\
\hline Unsuccessful paging & $\begin{array}{c}\text { Due to unsuccessful paging we have observed huge number of call failure same has } \\
\text { been escalated to RF and also LAC wise report developed to get paging failure in } \\
\text { detail. }\end{array}$ \\
\hline
\end{tabular}

\section{5. . System Performance and Control}

After detecting the root causes for low CSSR and taking apposite measures to fix them, this phase further exhibits the end result of process improvement and also tesimonials the implemented solution as a long lasting one and to become a usual practice in the day-to-day operation. We analyzed call failure before and after implementation as below.

Meet Error due to send routing info (SRI) failure: In order to check this error, MAP reports are analyzed and DN flag is changed. Once it is implemented, call failures before the measures taken and call failures after the measures adopted are compared and it is represented in Figure 11.

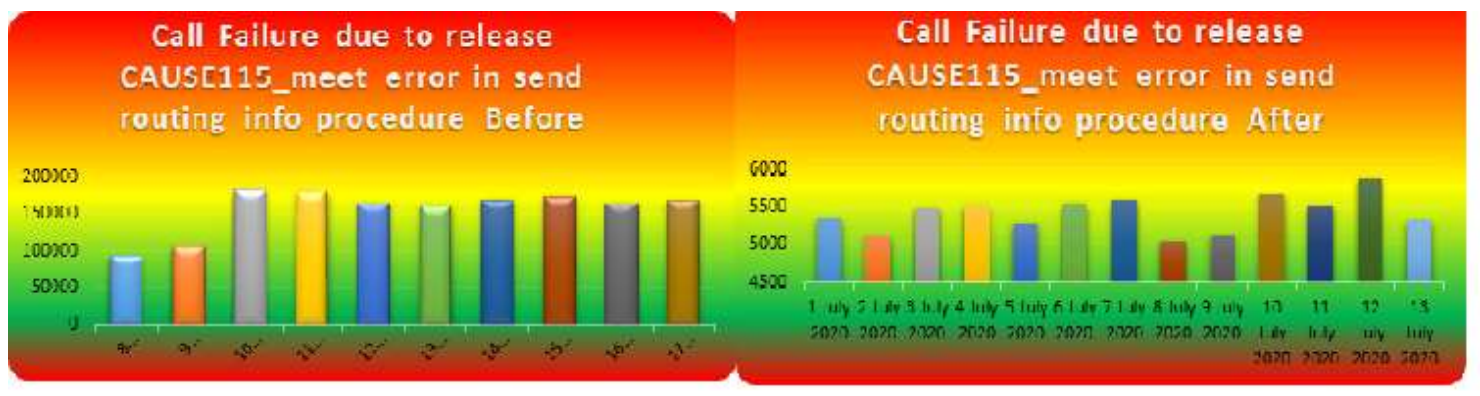

Figure 11. Meet Error due to SRI Failure.

The $\mathrm{X}$-axis of the graph indicates the date and $\mathrm{Y}$-axis represents the number of call failures, it is clear from the graph that, in November 2019, the daily call failures were 93584, 105015, 180307 and so. However, after CAUSE115 is fixed, CAUSE115 is system code of SRI failure, the call failures in July 2020 are recorded as 5355, 5127, 5493...... signifies a reduction of call failures around $95 \%$.

No Route to Applied circuit available: After countering this particular issue, we have compared the call failures before and after and it is represented in Figure 12. In first week of November 2019, the number of daily call failures were $44758,40644,43634,43699 \ldots$ and so on. However, after checking this issue, in July 2020, the daily call failures were reduced to $31862,31870,35301 \ldots$ reflecting an average drop of failures by $25 \%$. 


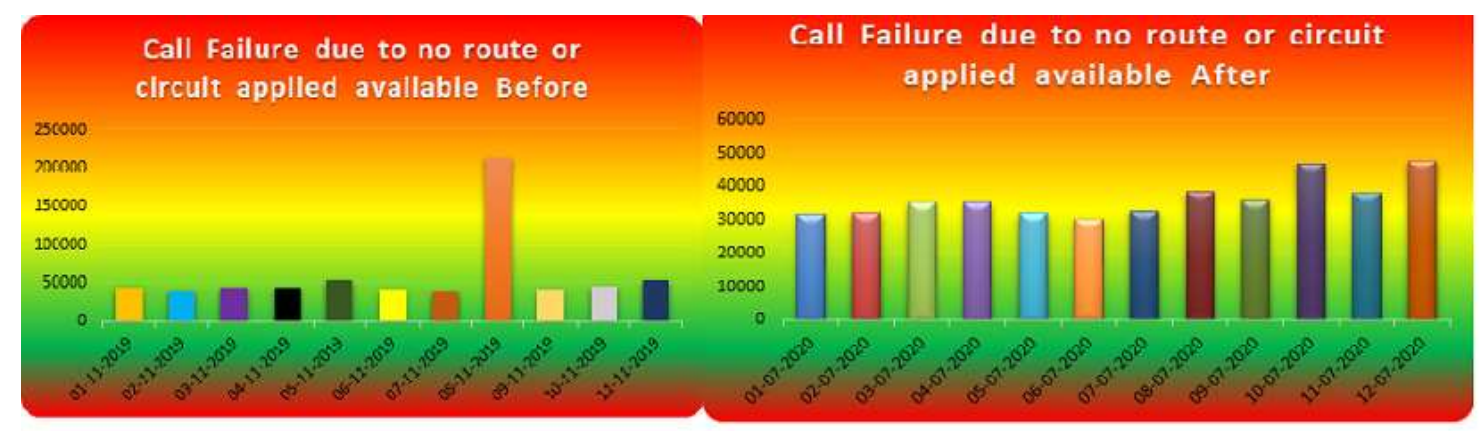

Figure 12. Call Failure due to no route to applied circuit available.

Termination Error: Once the measures were taken for checking this error, resultant affect was measured subsequently by percentage of call drop before and afterwards and it is represented in Figure 13. Y-axis stands for call failure percent and X-axis symbolize the date of failure. In November first week, failures were calculated a $0.212 \%, 0.209 \%$, $0.204 \% \ldots$ and so on. However, after fine tuning, in July 2020, the value was reduced to $0.165 \%, 0.168 \%, 0.171 \% \ldots$ etc

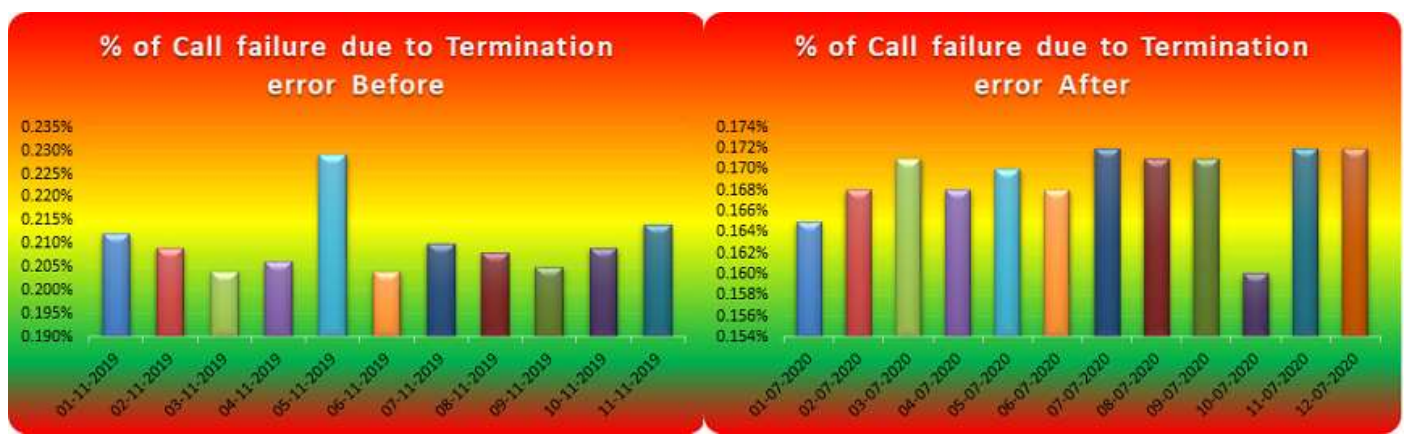

Figure 13. Call Failure due to Termination Error.

Similarly, the measures were taken for other vital parameters also based on the recommended solution in order to reduce the call failures. Furthermore, an action plan characterized by the individual parameter's improvement modalities has been constitutedd, for implementing and maintaining the process for the next three months. Figure 14 shows the control chart, for pre and post implementation. It is obvious that average CSSR is increased from $99.71 \%$ (Baseline) to $99.97 \%$ (After improvement) and the achieved CSSR keeps constant for three consecutive months.

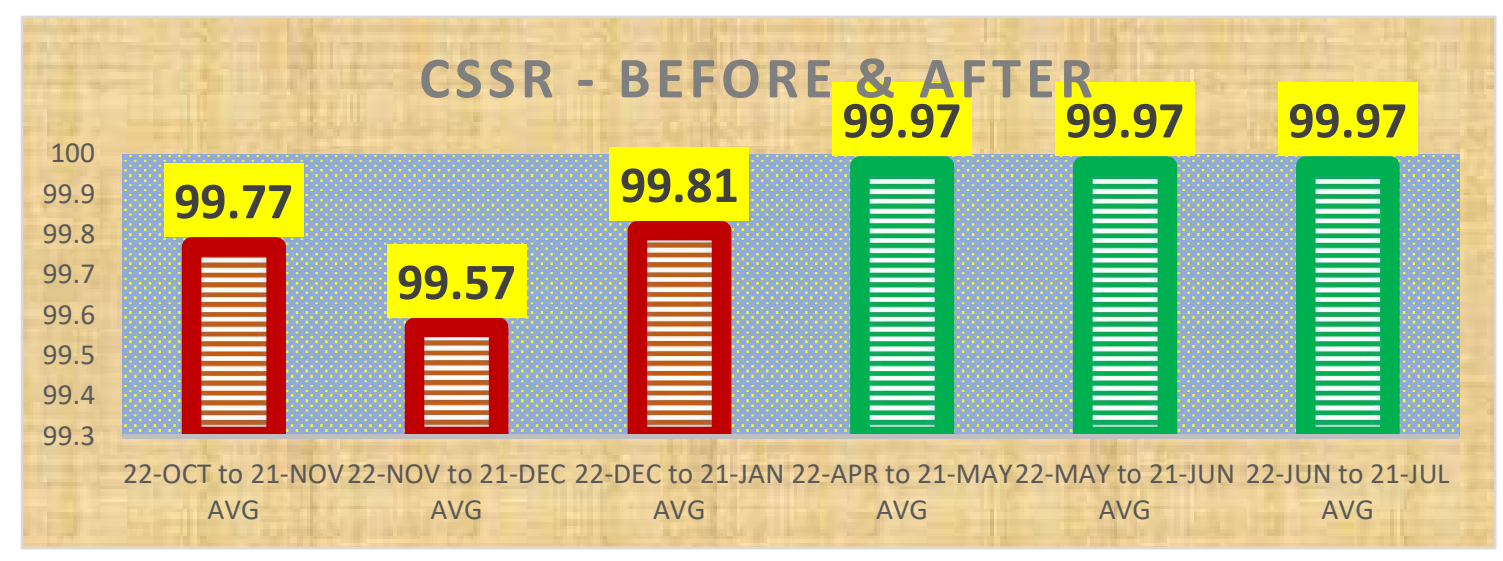

Figure 14. CSSR control chart. 
The improvement of average CSSR in phases are also exhibited in Figure 15 as the form of Boxplot and in Figure 16 in continuous cycles
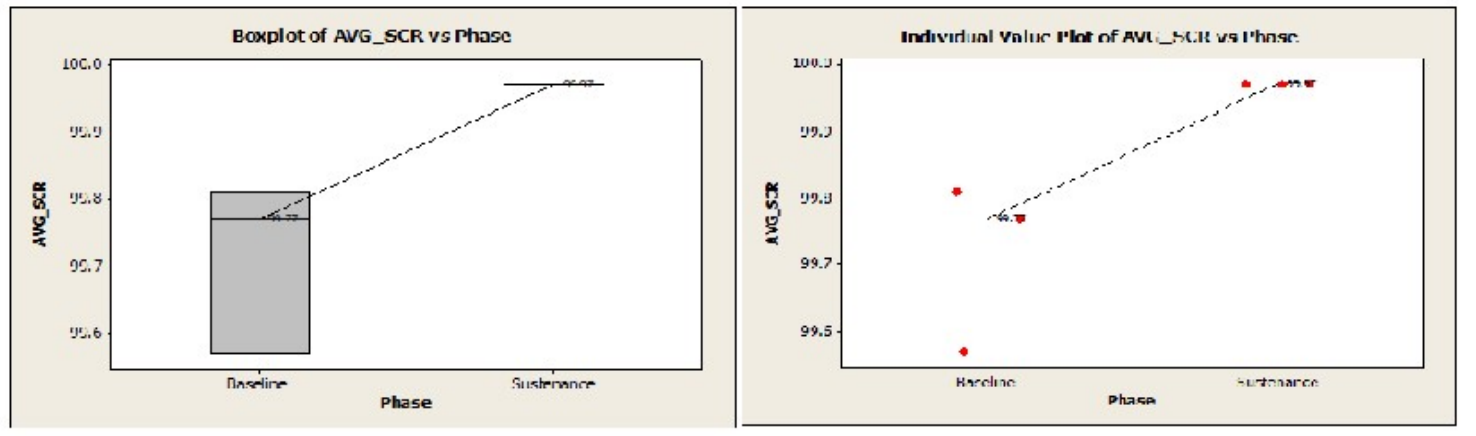

Figure 15. Average CSSR improvement

Mood Median Test: AVG_SCR versus Phase

Mood median test for AVG_SCR

Chi-Square $=6.00 \quad \mathrm{DF}=1 \quad \mathrm{P}=0.014$

Individual $95.0 \% \mathrm{CIs}$

Phase

$\mathrm{N}<=\mathrm{N}>$ Median Q3-Q1

Baseline

$\begin{array}{llll}3 & 0 & 99.770 & 0.240\end{array}$

Sustenance

$\begin{array}{llll}0 & 3 & 99.970 & 0.000\end{array}$
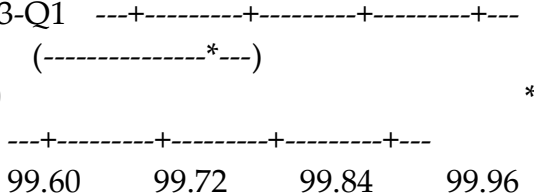

Overall median $=99.890$

* NOTE * Levels with $<6$ observations have confidence $<95.0 \%$

A $89.8 \%$ CI for median (Baseline) - median (Sustenance): $(-0.400,-0.160)$

\section{Conclusion}

Every invention inspired for easiness to facilitate the overcoming procedures which are faced in different kind of activities or field. In such process, machineries, instruments and other ancillary provisions are also taken up and achieved. In other words, subsequent to invention, it is intended for faultless instrumentation and operation procedure. In such a course in every field fault, failures in mechanism, instrumentation efficiencies and other related things are bound to be experienced. Hence it is necessary to find its causes, consequences and eradication afresh always and periodically. In case of CSSR, it is also applicable and cannot be exception as CSSR many times experienced failure. Therefore, the causes of its failure are searched for in case of searching it becomes necessary to reduce such procedure into a database system. To do so phase wise experiment was necessary. Hence every day during peak period, different types of causes for failure in CSSR were noted for the period of seven days against these causes rectifications were also noted simultaneously. Thereafter, an average was calculated for different causes of failure and also post rectification. Accordingly, the data was maintained and the same procedure was again repeated. It is important to mention here that after rectification, there was a decrease in failure causes.

Therefore, to achieve zero faults we have to strive hard, and Devop's mind are required for rectification for no fault, which seems not that easy. However, there is every possibility that faults may tend to zero. This is only possible when in the innovation of new technology, 5G application is improved to achieve fault -free driving with introduction of Advanced Network, mmWave System, Multi-radio Access, Advanced MIMO, Multiple Access, Advanced D2D, Network Slicing and Advanced Small Cell. Clearly, it is a continuous journey in the path of improvement, and therefore, it has to be continued 
with more and more innovations to achieve development in mobile communication where there will be no failure in CSSR. This process has to be continued thus we achieve the ways and means to make an error -free communication system in place.

Author Contributions: Conceptualization, M.M.; methodology, M.M.; software, T.D.; validation, M.M. and T.D.; formal analysis, M.M. and D.N.J.; investigation, K.S.; data curation, M.M.; writing - original draft preparation, M.M. and T.D.; writing - review and editing, K.S. and Y.H.; visualization, K.S..; supervision, D.N.J.; project administration, M.M.; funding acquisition, D.N.J. All authors have read and agreed to the published version of the manuscript.

\section{Funding:}

Conflicts of Interest: The authors declare no conflict of interest.

\section{References}

1. U.N. Kar and D.K. Sanyal , “An overview of device-to-device communication in cellular networks," ICT express, vol. 4, no.4, pp. 203-208, 2018

2. S. I. Popoola, A.A. Atayero, N. Faruk, and J. A. Badejo, "Data on the key performance indicators for quality of service of GSM networks in Nigeria," Data in brief, vol. 16, pp. 914-928, 2018.

3. O. Nyarko-Boateng and A. F. Adekoya, "Evaluation and Analysis of Key Performance Indicators Which Affect QoS of Mobile Call Traffic," International Journal of Computer Networks, vol.9, no.1, pp.14-30, 2019.

4. J. J. Popoola, I. O. Megbowon, and V.S. A. Adeloye, “Performance Evaluation and Improvement on Quality of Service of Global System for Mobile Communications in Nigeria," Journal of Information Technology Impact, vol. 9, no. 2, pp. 91-106, 2009.

5. V. P. Kumar, B. Anuradha, and V. Naresh, "Improvement of key performance indicators and QoS evaluation in operational GSM network," International Journal of Engineering Research and Applications, vol.1, no.3, pp. 411-417, 2012.

6. A. Trimarjoko, H. H. Purba, and A. Nindiani, "Consistency of DMAIC phases implementation on Six Sigma method in manufacturing and service industry: a literature review," Management and Production Engineering Review, vol. 11, 2020.

7. R. S. Peruchi, P. Rotela Junior, T. G. Brito, A. P. Paiva, P. P. Balestrassi, and L. M. M. Araújo, "Integrating Multivariate Statistical Analysis Into Six Sigma DMAIC Projects: A Case Study on AISI 52100 Hardened Steel Turning," IEEE Access, vol. 8, pp. 3424634255, 2020.

8. K. K. Chang and F.K. Wang, "Applying Six Sigma methodology to collaborative forecasting," Int. Journal of Advanced Mfg. Tech., vol. 39, no. 9, pp. 1033-1044, 2008.

9. S. Deniz and M. Cimen, Barriers of six sigma in healthcare organizations, Management Science Letters, vol.8, no.9, pp.885-890, 2018

10. P. Manchosu , G. Nicolini , G. Goretti , F. De Rose , D. Franceschini , C. Ferrari, G. Reggiori , S. Tomatis, and M. Scorsetti , "Applying Lean-Six-Sigma Methodology in radiotherapy: Lessons learned by the breast daily repositioning case," Radiotherapy and Oncology, vol.127, no.2, pp. 326-331, 2018.

11. C. G. Ekinci, M. T. Taner, and E. Erbas, “Integration of Six Sigma methodology to reduce complications in a private hemodialysis center," Int. Review of Mgt. and Marketing, vol. 5, no. 1, pp.36-44, 2015.

12. M. S. Y. Almasarweh and A. M. Rawashdeh, "The effect of using Six Sigma methodologies on the quality of health service: a field study at Prince Hashem hospital/city of Aqaba," Journal of Social Sciences, vol. 5, no. 3, pp.396-407, 2016.

13. G. Arcidiacono and A. Pieroni, "The revolution Lean Six Sigma 4.0," Int. Journal on Advanced Sci. Eng. Information Tech., vol. 8, no.1, pp.141-149, 2018.

14. G. Tetteh, “Improving learning outcome using Six Sigma methodology,” Journal of Int. Edu. in Business, vol.8, no.1, pp.18-36, 2014.

15. D. S. Kim, "Eliciting Success Factor of Applying Six Sigma in an Academic Library: a case study," Performance Measurement \& Metrics, vol.11, pp. 25-38, 2010

16. T. Chow and C.G. Downing, "A case for implementing Six Sigma improvement methodology in academia." In IIE Annual Conference. Proceedings, Institute of Industrial and Systems Engineers (IISE), 2014, pp. 1089-1097.

17. M. Maciel-Monteon, J. Limon-Romero, C. Gastelum-Acosta, D. Tlapa, Y. Baez-Lopez and H. A. Solano-Lamphar, "Measuring Critical Success Factors for Six Sigma in Higher Education Institutions: Development and Validation of a Surveying Instrument," IEEE Access, vol. 8, pp. 1813-1823, 2020, doi: 10.1109/ACCESS.2019.2962521

18. Z. Zhuo, "Research on using Six Sigma management to improve bank customer satisfaction," Int. Journal of Quality Innovation, vol.5, no. 3, pp.1-14, 2019.

19. M. D. Nayeri and M. Rostami, "Effectiveness of Six Sigma methodology through BSC in banking industry," Journal of Asian Business Strategy, vol. 6, no.1, pp. 13-21, 2016.

20. P.G. Psychogios, J. Atanasovski, and L. K. Tsironis, “Lean Six Sigma in a service context a multi-factor application approach in the telecommunications industry," Int. Journal of Quality \& Reliability Mgt., vol. 29, no.1, pp.122-139, 2012.

21. H. U. Rahman, M. Asif, M. A. Saeed, M. A. Akbar, and M. U. Awan, "Application of Six Sigma at cell site construction: a case study," Asian Journal on Quality, vol.13, no.3, pp. 212-233, 2012. 
22. L. G. Guti'errez, S. D. Leeuw, and R. Dubbers, “Logistics services and Lean Six Sigma implementation: a case study," Int. Journal of Lean Six Sigma, vol.7, no.3, pp. 324-342, 2016.

23. A. Zhang, W. Luo, S.T. Chia, and Z. H. Sim, "Lean and Six Sigma in logistics: a pilot survey study in Singapore," Int. Journal of Opr. \& Production Mgt., vol.36, no.11, pp.1-21, 2016.

24. A. George, A.M. Joseph, S. Kolencherry, V. V. Kodath, K. Menaka, B. Duraisingh, ... and T. Shivakumar, "Application of Six Sigma DMAIC methodology to reduce medication errors in a major trauma care centre in India." Indian Journal of Pharmacy Practice, vol.11, no.4, pp.182-187, 2018.

25. M. S. I. Khan, S. Sushil, and S. R. Tushar, "Minimization of defects in the fabric section through applying DMAIC methodology of Six Sigma: a case study," Asian Journal of Management Sciences \& Education," vol.9, no.3. pp. 16-24, 2020.

26. J. Kansal and S. Singhal, "Application and Validation of DMAIC Six Sigma Tool for Enhancing Customer Satisfaction in a Government R\&D Organization," International Journal for Quality Research, vol. 11, no.4, pp.931-944, 2017.

27. V. Gupta, R. Jain, M. L. Meena, and G. S. Dangayach, Six-sigma application in tire-manufacturing company: a case study, J Ind Eng Int, vol. 14, pp. 511-520, 2018.

28. F. M. E. Uzoka, J. Osuji, and O. Obot, "Clinical decision support system (DSS) in the diagnosis of malaria: A case comparison of two soft computing methodologies," Expert Systems with Applications, vol. 38, pp.1537-1553, 2011.

29. R. Kumar, A. Irshad Khan, Y. B. Abushark, M. M. Alam, A. Agrawal, and R. A. Khan, "An Integrated Approach of Fuzzy Logic, AHP and TOPSIS for Estimating Usable-Security of Web Applications," IEEE Access, vol. 8, pp. 50944-50957, 2020.

30. A. Mohapatro, S.K. Mahendran, and T.K. Das, "Clinical Decision Support System for Detection of Dengue - A Case Comparison using AHP and Fuzzy AHP," J. of cases in IT, vol.23, no. 4, 2021, Art. no. 5.

31. R. Raman and Y. Basavaraj, "Defect reduction in a capacitor manufacturing process through Six Sigma concept: A case study,"Management Science Letters, vol.9, no.2, pp.253-260, 2019. 